\title{
Population-based study of the association between asthma and pneumococcal disease in children
}

This article was published in the following Dove Press journal:

Clinical Epidemiology

15 July 2015

Number of times this article has been viewed

\author{
Kimberly M Shea ${ }^{1,2}$ \\ Timothy L Lash ${ }^{3,4}$ \\ Sussie Antonsen ${ }^{4}$ \\ Susan S Jick ${ }^{1,5}$ \\ Henrik T Sørensen ${ }^{1,4}$ \\ 'Department of Epidemiology, Boston \\ University School of Public Health, \\ ${ }^{2}$ Department of Pediatrics, Boston \\ University School of Medicine, Boston, \\ MA, ${ }^{3}$ Department of Epidemiology, \\ Rollins School of Public Health, \\ Emory University, Atlanta, GA, USA; \\ ${ }^{4}$ Department of Clinical Epidemiology, \\ Aarhus University Hospital, Aarhus, \\ Denmark; ${ }^{5}$ Boston Collaborative \\ Drug Surveillance Program, Boston \\ University, Boston, MA, USA
}

Background: Although asthma has recently been established as a risk factor for pneumococcal disease (PD), few studies have specifically evaluated this association in children.

Methods: We conducted a nation-wide population-based cohort study of the effect of asthma on childhood PD among all singleton live births in Denmark from 1994 to 2007, before the introduction of the 7-valent pneumococcal conjugate vaccine. All data were abstracted from Danish medical registries. Because underlying comorbidity substantially increases the PD risk in children, standard methods were used to assess the evidence of biologic interaction between comorbidity and asthma on the risk of PD.

Results: There were 2,253 cases of childhood PD among 888,655 children born in Denmark from 1994 to 2007. The adjusted incidence rate ratio of the effect of asthma on childhood PD was 2.2 (95\% confidence interval [CI]: 2.0, 2.5). Age-stratified incidence rate ratios were $2.1(95 \%$ CI: $1.8,2.9)$ in children 6 months to $<24$ months, $4.1(95 \%$ CI: $3.3,5.1)$ in children 24 months to $<60$ months, and 2.3 (95\% CI: 1.6, 3.2) in children $\geq 60$ months. Evaluation of the biologic interaction between asthma and comorbidity in older children revealed that $55 \%$ (24 months to $<60$ months) to $73 \%$ ( $\geq 60$ months) of cases among asthma-exposed children can be accounted for by the interaction between asthma and comorbidity.

Conclusion: These results confirm that asthma is an important risk factor for PD in children and suggest that children with underlying comorbidities are more sensitive to the effect of asthma on PD than children without comorbidities.

Keywords: pneumococcal disease, asthma, comorbidity, children

\section{Introduction}

Streptococcus pneumoniae is a leading cause of serious illness worldwide. Pneumococcal infections are especially dangerous for children and adults with immunodeficiencies, such as HIV, or with illnesses such as chronic cardiac disease and diabetes. ${ }^{1}$ Pneumococcal vaccination has therefore been recommended for persons at high risk of severe illness or complications.

Asthma was first identified as an independent risk factor for pneumococcal disease (PD) in 2005 when Talbot et $\mathrm{al}^{2}$ reported that asthma was associated with a 2.4-fold increased odds of PD among persons 2-49 years old enrolled in Tennessee's Medicaid Program between 1994 and 2002. Several studies conducted since then have provided additional evidence that asthma is associated with an increased risk of PD in adults, ${ }^{3-5}$ but no study has provided convincing evidence that asthma is associated with an increased risk of PD in children. ${ }^{6}$

Currently, pneumococcal vaccination is recommended for asthmatic adults, but it is not specifically recommended for asthmatic children. Asthma is the most common
Correspondence: Kimberly M Shea Department of Epidemiology, Boston University School of Public Health, 7I5 Albany Street, Boston, MA 02118, USA

Tel + I 6176387725

Fax +l 6176384458

Email kimshea@bu.edu 
chronic disease in children, ${ }^{7}$ and the prevalence of asthma is increasing worldwide..$^{8-12}$ As the prevalence of asthma increases, so does the importance of understanding whether children with asthma are at increased risk of PD. The aim of the current study was to evaluate the association between asthma and the development of PD among Danish children born between 1994 and 2007.

\section{Methods}

\section{Study population}

The study population included all singleton live births in Denmark from January 1, 1994 through December 31, 2007. Routine childhood pneumococcal vaccination with 7-valent pneumococcal conjugate vaccine (PCV7) did not begin in Denmark until October 2007, ${ }^{13}$ so few children in the study population were expected to be vaccinated. We used the unique Civil Personal Registry number assigned to all Danish citizens at birth and to residents upon immigration, which has been used in public records since 1968, to identify all live births from the Danish Civil Registration System. This continually updated national registration system includes information about date and place of birth, immigration, sex, marital status, citizenship, emigration, and vital status. ${ }^{14}$ All study children were followed from birth until the diagnosis of PD, removal from the Danish Civil Registration System due to any cause, or December 31, 2007, whichever came first. The Danish Data Protection Agency provided permission to use these data (record number: 1-16-02-108). Because this study was based on data extracted from registries, it was exempt from human subjects review, and members of the study population did not have to provide informed consent.

\section{Data collection}

To ascertain PD, we used each subject's unique Civil Personal Registry number to link their Danish Civil Registration System data to the Danish National Registry of Patients. The Danish National Registry of Patients began in 1977 and includes inpatient diagnoses made at nonpsychiatric hospitals and, beginning in 1995, diagnoses made at outpatient specialist clinics and emergency room visits. ${ }^{15} \mathrm{We}$ used the Danish version of International Classification of Diseases (ICD)-10 codes G00.1, A40.3, and J13.9 to ascertain pneumococcal meningitis, pneumococcal septicemia, and pneumococcal pneumonia, respectively. Diagnosis of pneumococcal pneumonia using these ICD codes was validated in a prior study in which $64 \%$ of ICD-10-identified cases had microbiologic, radiologic, and clinical evidence consistent with $\mathrm{PD}$, and the remaining $36 \%$ were classified as having probable PD. ${ }^{16}$

We used ICD-10 codes (J45 and J46) recorded in the Danish National Registry of Patients to ascertain asthma. Registry-based asthma diagnoses have been previously validated in Denmark and determined to be of high quality. ${ }^{17,18}$ We classified study subjects as having asthma if they had at least one diagnosis code indicating asthma hospitalization, emergency, or outpatient visits at any time before the diagnosis of PD, or before the end of follow-up for children who did not develop PD.

Information obtained from the Danish Medical Birth Registry included place of birth, gestational age, fetal presentation, mode of delivery, birth weight, 5-minute Apgar score, maternal place of birth, maternal age at the time of delivery, maternal cohabitation status, and maternal parity. ${ }^{19}$ Maternal smoking status during pregnancy was based on self-report during the first antenatal visit and was classified as yes or no, and presence or absence of congenital malformations or selected underlying comorbidities was ascertained using ICD-10 codes recorded in the Danish National Registry of Patients (Table S1).

\section{Statistical analyses}

Children accumulated unexposed person-time from birth until an asthma diagnosis, if any, and exposed person-time thereafter. We calculated the frequency and proportion of children with and without asthma within categories of demographic variables and birth outcomes, as well as age-specific incidence rates of PD.

We used Poisson regression to estimate crude and adjusted incidence rate ratios (IRRs) and 95\% confidence intervals (CIs) associating childhood asthma and PD. We included covariates that changed the crude association between asthma and PD by more than $10 \%$ in adjusted models; child's sex was retained in the adjusted models regardless of its impact on the unadjusted measures.

Because underlying comorbidity is known to substantially increase the risk of PD in children, ${ }^{20}$ and because it was strongly associated with childhood asthma exposure in our study population, we evaluated the impact of comorbidity on the association between asthma and PD in stratified analyses. The impact of congenital malformations was also assessed. For these analyses, we used Poisson regression to calculate crude and adjusted IRRs and 95\% CIs stratified by the presence or absence of congenital malformations or selected underlying comorbidities. We further evaluated any observed effect measure modification for evidence of 
biologic interaction using standard measures (Supplementary materials). ${ }^{21,22}$

We conducted all statistical analyses using SAS/STAT ${ }^{\circledR}$ software, version 9.2 (SAS Institute Inc., Cary, NC, USA). ${ }^{23}$

\section{Results}

\section{Characteristics of the study population}

There were 890,681 singleton live births during the study period. After excluding 2,026 records, 888,655 births were included in the analysis. Records were excluded if a child had 0 days of follow-up (number $[\mathrm{n}]=1,228$ ), birth weight $<500 \mathrm{~g}$ ( $n=90)$, gestational age $<25$ completed weeks or $>45$ completed weeks ( $n=510$ and $n=5$, respectively), implausible gestational age and birth weight combinations $(n=70)$, or if they met $>1$ exclusion criteria $(n=123)$. The mean and median follow-up periods were both 8.0 years (interquartile range: $4.4-11.6$ years).

Among the 888,655 children in the study population, $6.0 \%$ $(n=53,024)$ received an asthma diagnosis before the end of follow-up. The mean age of asthma diagnosis was 31 months (standard deviation: \pm 31.0 months), and the median was 18.7 months (interquartile range: $10.7-39.6$ months). A total of 6,641 children had a recorded comorbidity; cardiac disease was the most common comorbidity (32.8\%), followed by renal disease (21.5\%) and type 1 diabetes (20.3\%).

Compared with children without asthma, children with an asthma diagnosis were more likely to be male, to have been born preterm ( $<37$ weeks), to have a low birth weight $(<2,500$ $\mathrm{g}$ ), and to be born to a mother who reported smoking at the first prenatal visit (Table 1). In addition, asthmatic children had more congenital malformations $(6.7 \%$ versus $4.4 \%$, respectively) and selected underlying comorbidities $(2.4 \%$ versus $0.6 \%$, respectively) compared with nonasthmatic children.

A total of 2,253 children were diagnosed with PD during the follow-up period, and most of them were admitted as inpatients (96.3\%). Pneumonia accounted for the majority of cases $(72.9 \%)$, followed by septicemia (14.6\%) and meningitis (12.5\%). Most PD diagnoses occurred between 6 months and 24 months after birth $(n=1,180 ; 52.7 \%)$ and the fewest occurred at more than 60 months after birth $(n=255$; $11.3 \%$ ). There was no trend toward increasing or decreasing incidence throughout the study's calendar period.

\section{Age-specific PD incidence}

Age-specific incidence rates for PD are presented in Table 2. The rate of PD was highest among children 6 to $<24$ months old (91.2 cases per 100,000 child-years) followed by children 0 to $<6$ months old ( 78.8 cases per 100,000 child-years) and children 24 to $<60$ months old ( 21.5 cases per 100,000 child-years). Children in the oldest age group had the lowest PD rates ( 8.0 cases per 100,000 child-years). PD incidence rates in asthmatic children were consistently higher than in nonasthmatic children, with the exception of children aged 0 to $<6$ months.

\section{Association between asthma and PD}

The unadjusted IRR associating asthma with incident PD among all children was 2.4 (95\% CI: 2.1, 2.6). Age-specific measures of association were confounded by year of birth, birth weight, congenital malformations, and underlying comorbidities. These confounders and child's sex were therefore included in adjusted analyses. The adjusted IRR associating asthma with incident PD among all children was 2.2 (95\% CI: 2.0, 2.5); in order of increasing age strata, the adjusted IRRs were $0.4(95 \% \mathrm{CI}: 0.2,0.8)$ in children 0 to $<6$ months old, $2.1(95 \% \mathrm{CI}: 1.8,2.5)$ in children 6 to $<24$ months old, 4.1 (95\% CI: 3.3, 5.1) in children 24 to $<60$ months old, and 2.3 (95\% CI: $1.6,3.2)$ in children $\geq 60$ months old (Table 2).

Restricting the study population to children without selected comorbidities or malformations did not substantially change the IRRs associating asthma with incident PD in any age strata. Restricting the study population to children who did have selected comorbidities or malformations, however, revealed that comorbidity was an effect modifier of the association between asthma and PD in children aged 24 to $<60$ months and $\geq 60$ months (Table 3 ).

Evaluation of biologic interaction between asthma and comorbidity on the incidence of PD in these age groups showed that the rate of PD was greater among those with a recorded diagnosis of both asthma and comorbidity compared with the rate that would be expected based on the independent effects of asthma or comorbidity alone. Figure 1 shows that among children aged 24 to $<60$ months old, the unadjusted incidence rate of PD in children with both asthma and comorbidity was 7.5 times the rate in children with asthma alone, and that after adjusting for confounding variables, 55\% (95\% CI: $31,79)$ of PD cases among asthmatic children could be attributed to the presence of both asthma and comorbidity at the same time. Among children aged $\geq 60$ months old, the unadjusted IRR of PD in children with both asthma and comorbidity was 14 times the rate in children with asthma alone, and the adjusted percentage of PD cases attributable to biologic interaction increased to $73 \%(95 \%$ CI: 52, 93). 
Table I Selected characteristics of live births, Denmark, 1994-2007

\begin{tabular}{|c|c|c|c|c|c|c|}
\hline & \multicolumn{2}{|l|}{ Overall } & \multicolumn{2}{|c|}{ Child asthma } & \multicolumn{2}{|c|}{ No child asthma } \\
\hline & $\mathbf{n}$ & $\%$ & $\mathbf{n}$ & $\%$ & $\mathrm{n}$ & $\%$ \\
\hline Characteristics & 888,655 & 100 & 53,024 & 100 & 835,631 & 100 \\
\hline \multicolumn{7}{|l|}{ Child's sex } \\
\hline Male & 456,001 & 51.3 & 33,790 & 63.7 & 422,211 & 50.5 \\
\hline Female & 432,654 & 48.7 & 19,234 & 36.3 & 413,420 & 49.5 \\
\hline \multicolumn{7}{|l|}{ Home birth } \\
\hline No & 880,712 & 99.1 & 52,646 & 99.3 & 828,066 & 99.1 \\
\hline Yes & 7,943 & 0.9 & 378 & 0.7 & 7,565 & 0.9 \\
\hline \multicolumn{7}{|l|}{ Gestation } \\
\hline Term ( $\geq 37$ weeks) & 840,509 & 94.6 & 48,311 & 91.1 & 792,198 & 94.8 \\
\hline Preterm ( $<37$ weeks) & 48,146 & 5.4 & 4,713 & 8.9 & 43,433 & 5.2 \\
\hline \multicolumn{7}{|l|}{ Fetal presentation } \\
\hline Cephalic & 847,165 & 96.1 & 50,168 & 95.3 & 796,997 & 96.1 \\
\hline Breech, other & 34,794 & 3.9 & 2,498 & 4.7 & 32,296 & 3.9 \\
\hline \multicolumn{7}{|l|}{ Mode of delivery } \\
\hline Vaginal & 692,673 & 77.9 & 40,442 & 76.3 & 652,231 & 78.1 \\
\hline Cesarean & 128,240 & 14.4 & 8,743 & 16.5 & 119,497 & 14.3 \\
\hline Forceps, vacuum & 67,742 & 7.6 & 3,839 & 7.2 & 63,903 & 7.6 \\
\hline \multicolumn{7}{|l|}{ Birth weight } \\
\hline Normal ( $\geq 2,500 \mathrm{~g})$ & 852,004 & 95.9 & 49,379 & 93.1 & 802,625 & 96.1 \\
\hline Low $(<2,500 \mathrm{~g})$ & 36,651 & 4.1 & 3,645 & 6.9 & 33,006 & 3.9 \\
\hline \multicolumn{7}{|l|}{ 5-minute Apgar score } \\
\hline Normal $(\geq 7)$ & 872,416 & 99.2 & 51,934 & 98.9 & 820,482 & 99.2 \\
\hline Below normal $(<7)$ & 6,959 & 0.8 & 561 & I.I & 6,398 & 0.8 \\
\hline \multicolumn{7}{|l|}{ Maternal place of birth } \\
\hline Denmark & 770,497 & 86.7 & 46,677 & 88.0 & 723,820 & 86.6 \\
\hline Other country & 118,158 & 13.3 & 6,347 & 12.0 & ||$|, 8| \mid$ & 13.4 \\
\hline \multicolumn{7}{|l|}{ Maternal age at delivery } \\
\hline$<20$ years & 27,201 & 3.1 & 2,291 & 4.3 & 24,910 & 3.0 \\
\hline $21-35$ years & 765,090 & 86.1 & 45,957 & 86.7 & 719,133 & 86.1 \\
\hline$>35$ years & 96,364 & 10.8 & 4,776 & 9.0 & 91,588 & 11.0 \\
\hline \multicolumn{7}{|l|}{ Maternal parity } \\
\hline Primiparous & 398,450 & 44.8 & 22,279 & 42.0 & 376,171 & 45.0 \\
\hline Multiparous & 490,205 & 55.2 & 30,745 & 58.0 & 459,460 & 55.0 \\
\hline \multicolumn{7}{|c|}{ Maternal cohabitation status } \\
\hline No & 144,202 & 17.4 & $\mathrm{II}, 017$ & 21.5 & 133,185 & 17.2 \\
\hline Yes & 682,901 & 82.6 & 40,292 & 78.5 & 642,609 & 82.8 \\
\hline \multicolumn{7}{|c|}{ Maternal smoking status at pregnancy } \\
\hline No & $667,|4|$ & 78.2 & 34,674 & 68.6 & 632,467 & 78.8 \\
\hline Yes & $|86,07|$ & 21.8 & 15,849 & 31.4 & 170,222 & 21.2 \\
\hline \multicolumn{7}{|l|}{ Congenital malformation } \\
\hline No & 848,600 & 95.5 & 49,479 & 93.3 & 799,121 & 95.6 \\
\hline Yes & 40,055 & 4.5 & 3,545 & 6.7 & 36,510 & 4.4 \\
\hline \multicolumn{7}{|l|}{ Underlying comorbidity } \\
\hline No & 882,014 & 99.3 & 51,770 & 97.6 & 830,244 & 99.4 \\
\hline Yes & 6,641 & 0.7 & $\mathrm{I}, 254$ & 2.4 & 5,387 & 0.6 \\
\hline
\end{tabular}

Abbreviation: $\mathrm{n}$, number.

\section{Discussion}

This study provides evidence that asthma is an important risk factor for the development of PD in children, and it provides new insight about a potentially meaningful interaction between asthma and comorbidity on the risk of PD.

Consistent with data presented by Talbot et al, ${ }^{2}$ we observed a twofold increased rate of $\mathrm{PD}$ among all children $<18$ years old following a childhood asthma diagnosis compared with person-time before an asthma diagnosis or in children who never had an asthma diagnosis after adjusting for confounding factors. The highest rate ratio occurred among children 24 to $<60$ months old, which was twice as large as the rate ratios observed among children 6 to $<24$ months old and $\geq 60$ months old. We also observed a rate ratio less than 
Table 2 Pneumococcal disease incidence rates per 100,000 child-years and IRRs of the association between childhood asthma and incident pneumococcal disease, Denmark, 1994-2007

\begin{tabular}{|c|c|c|c|c|c|c|c|}
\hline & Cases & Person-years & $\begin{array}{l}\text { Rate per } 100,000 \\
\text { child-years }\end{array}$ & IRR & $95 \% \mathrm{Cl}$ & $\begin{array}{l}\text { Adjusted } \\
\text { IRR }^{\mathbf{a}}\end{array}$ & $95 \% \mathrm{Cl}$ \\
\hline \multicolumn{8}{|l|}{ Age group } \\
\hline Asthma & 319 & 465,381 & 69 & 2.4 & $2.1-2.6$ & 2.2 & $2.0-2.5$ \\
\hline No asthma & 1,934 & $6,619,575$ & 29 & Ref & - & Ref & - \\
\hline \multicolumn{8}{|c|}{0 to $<6$ months old } \\
\hline Asthma & 9 & 26,565 & 34 & 0.4 & $0.2-0.8$ & 0.4 & $0.2-0.8$ \\
\hline No asthma & 341 & $4|7,4| 4$ & 82 & Ref & - & Ref & - \\
\hline \multicolumn{8}{|c|}{6 to $<24$ months old } \\
\hline Asthma & 153 & 78,717 & 194 & 2.3 & $1.9-2.7$ & 2.1 & I.8-2.5 \\
\hline No asthma & I,027 & $|2|, 520$ & 85 & Ref & - & Ref & - \\
\hline \multicolumn{8}{|c|}{24 to $<60$ months old } \\
\hline Asthma & 116 & 139,975 & 83 & 4.8 & $3.9-6.0$ & 4.1 & $3.3-5.1$ \\
\hline No asthma & 351 & 203,120 & 17 & Ref & - & Ref & - \\
\hline \multicolumn{8}{|c|}{$\geq 60$ months old } \\
\hline Asthma & 41 & 220,124 & 19 & 2.6 & $1.8-3.6$ & 2.3 & $1.6-3.2$ \\
\hline No asthma & 214 & 295,575 & 7 & Ref & - & Ref & - \\
\hline
\end{tabular}

Note: aIRR adjusted for sex, year of birth weight, congenital malformations, and comorbidity.

Abbreviations: IRRs, incidence rate ratios; $\mathrm{Cl}$, confidence interval; Ref, reference.

1 among children 0 to $<6$ months old, but emphasize that we do not believe that this indicates that asthma is protective against PD in this age group. Instead, we suspect that this observation is due to the difficulty of reliably diagnosing asthma in very young children. ${ }^{24}$

The evaluation of a biological interaction between childhood asthma and comorbidity on the incidence of PD revealed that the combined effect of these two exposures was synergistic in older children, and that a high proportion $(55 \%$ in children aged 24 to $<60$ months, and $73 \%$ in children aged $\geq 60$ months) of the PD incidence among asthmatic children with comorbidities was attributable to this interaction. No synergy between childhood asthma and comorbidity was observed in children less than 2 years old. These results suggest that children more than 2 years old who have underlying comorbidities are more sensitive to the effect of asthma on PD than children more than 2 years old without comorbidities.

Juhn et al $^{3}$ also identified comorbidity as an effect modifier of the association between asthma and PD among Minnesota

Table 3 IRRs for the association between asthma and incident pneumococcal disease, stratified by comorbidity and congenital malformation among the two oldest age groups only, Denmark, 1994-2007

\begin{tabular}{|c|c|c|c|c|c|c|c|c|}
\hline & \multicolumn{4}{|c|}{24 to $<60$ months old } & \multicolumn{4}{|c|}{$\geq 60$ months old } \\
\hline & Cases & $\begin{array}{l}\text { Person- } \\
\text { years }\end{array}$ & $\begin{array}{l}\text { IRR } \\
(95 \% \mathrm{Cl})\end{array}$ & $\begin{array}{l}\text { Adjusted IRR } \\
(95 \% \mathrm{Cl})\end{array}$ & Cases & $\begin{array}{l}\text { Person- } \\
\text { years }\end{array}$ & $\begin{array}{l}\text { IRR } \\
(95 \% \mathrm{Cl})\end{array}$ & $\begin{array}{l}\text { Adjusted IRR } \\
(95 \% \mathrm{Cl})\end{array}$ \\
\hline \multicolumn{9}{|c|}{ IRR stratified by comorbidity } \\
\hline \multicolumn{9}{|c|}{ Comorbidity + present } \\
\hline Asthma + & 19 & 3,569 & $3.4(1.9-6.3)$ & $3.0(1.6-5.4)$ & 12 & 6,059 & $4.2(1.9-9.3)$ & $4.7(2.1-10.4)$ \\
\hline Asthma - & 24 & 15,450 & Ref & Ref & 13 & 27,857 & Ref & Ref \\
\hline \multicolumn{9}{|c|}{ No comorbidity - present } \\
\hline Asthma + & 97 & 136,407 & $4.4(3.5-5.6)$ & $4.2(3.4-5.3)$ & 29 & 214,065 & $2.0(1.3-2.9)$ & $1.9(1.3-2.9)$ \\
\hline Asthma - & 327 & $2,015,754$ & Ref & Ref & 201 & $2,927,900$ & Ref & Ref \\
\hline \multicolumn{9}{|c|}{ IRR stratified by congenital malformation } \\
\hline \multicolumn{9}{|c|}{ Malformation + present } \\
\hline Asthma + & 24 & 8,832 & $5.3(3.2-8.7)$ & $4.1(2.4-6.8)$ & 7 & 12,810 & $3.5(1.5-8.4)$ & $2.9(1.2-7.1)$ \\
\hline Asthma - & 43 & 83,515 & Ref & Ref & 18 & 115,835 & Ref & Ref \\
\hline \multicolumn{9}{|c|}{ malformation - present } \\
\hline Asthma + & 92 & $|3|, \mid 43$ & $4.5(3.6-5.7)$ & $4.1(3.2-5.2)$ & 34 & 207,315 & $2.4(1.7-3.4)$ & $2.2(1.5-3.1)$ \\
\hline Asthma - & 308 & $1,947,689$ & Ref & Ref & 196 & $2,839,922$ & Ref & Ref \\
\hline
\end{tabular}

Notes: aIRR adjusted for sex, birth weight, and child year of birth; comorbidity strata also adjusted for congenital malformation, and malformation strata also adjusted for comorbidity. The $(+)$ and $(-)$ symbols indicate that the children were either asthma positive or asthma negative.

Abbreviations: IRRs, incidence rate ratios; $\mathrm{Cl}$, confidence interval; Ref, reference. 
A

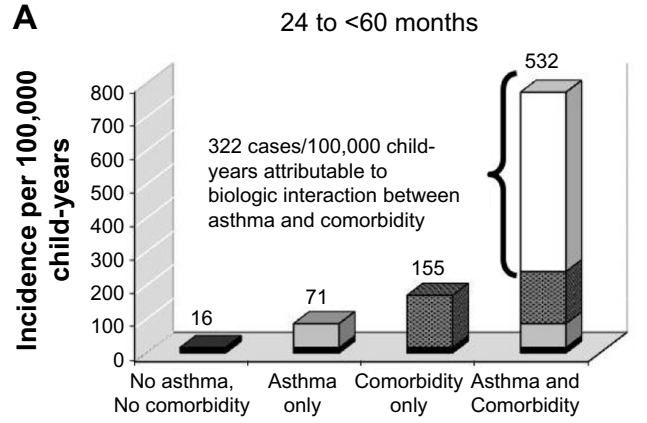

B

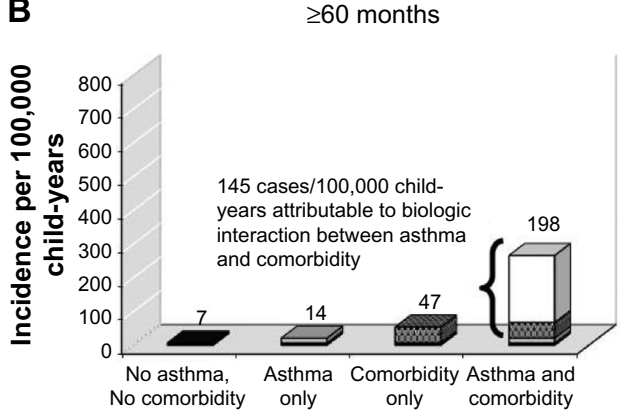

Figure I Biologic interaction between asthma and comorbidity on the risk of pneumococcal disease (PD), Denmark, 1994-2007.

Notes: (A) In children 24 to $<60$ months: the unadjusted incidence rate of PD in children with both asthma and comorbidity was 7.5 times the rate in children with asthma alone (532 cases versus 7 I cases per 100,000 child-years, respectively). After adjusting for sex, birth weight, child year of birth, and congenital malformation, $55 \%$ ( $95 \%$ $\mathrm{Cl}: 3 \mathrm{I}, 79)$ of PD cases in children with both asthma and comorbidity was attributable to biologic interaction. (B) In children $\geq 60$ months: the unadjusted incidence rate of PD in children with both asthma and comorbidity was 14 times the rate in children with asthma alone (198 cases versus 14 cases per 100,000 child-years, respectively). After adjusting for sex, birth weight, child year of birth, and congenital malformation, $73 \%(95 \% \mathrm{Cl}: 52,93)$ of PD cases in children with both asthma and comorbidity was attributable to biologic interaction.

Abbreviation: $\mathrm{Cl}$, confidence interval.

adults. They reported that the odds ratio (OR) of the effect of asthma on PD among adults with high-risk conditions was lower (OR: $1.2 ; P=0.86$ ) than the OR among those without high-risk conditions (OR: 2.9; $P=0.04$ ). Similar results were observed in our study in children between 2 years and 5 years old: the association between asthma and incident PD was lower among children with underlying comorbid conditions compared with children without underlying illnesses (adjusted IRR: 2.9 versus 4.2, respectively). The lower rate ratios among children with comorbid conditions probably results from their higher risk of PD, which is sometimes called modification by the baseline risk. Juhn et $\mathrm{al}^{3}$ did not assess for biological interaction on the additive scale in their study, and instead reported that there was no statistical interaction between asthma and illnesses based on the addition of an interaction term in a log-linear multivariate model. Departure from additivity is a better measure of biologic interaction, and a lack of statistical interaction - when measured as an interaction term in a log-linear multiplicative multivariate model - can easily be mistaken for a lack of biologic interaction. ${ }^{22}$

Several investigators have identified potential biologic mechanisms that may explain how asthma increases the risk of PD. Two studies have identified associations between asthma and increased carriage of Streptococcus pneumoniae in the nasopharynx,${ }^{25,26}$ suggesting that children with asthma may be at increased risk of PD because they are more likely to be colonized with pneumococci. Other proposed mechanisms include asthma-induced pathologic alterations that can impair clearance of pathogenic bacteria from the airway ${ }^{27,28}$ and chronic airway inflammation leading to impaired respiratory immunity. ${ }^{29,30}$

Several limitations should be considered when interpreting the results from this study. First, the use of registry-based
ICD-10 codes to identify children with asthma is likely to result in some misclassification. Underascertainment of asthma is possible if less severe cases of asthma were missed, most likely due to diagnosis or treatment only by a general practitioner. Such underascertainment would bias the IRRs describing the association between asthma and PD toward the null because some exposed children would be misclassified as unexposed. Overascertainment is also possible if some children with wheezing due to other causes, for example respiratory syncytial virus, were classified as having asthma. Although one way to increase sensitivity and specificity of asthma exposure would have been to incorporate the use of prescription asthma medications into a classification scheme for asthma exposure, we did not have access to these data for this study. We were also unable to include a mechanism by which to reclassify asthma-exposed children as unexposed if they "grew out" of an asthma diagnosis.

Although imperfect sensitivity and specificity of exposure classification is possible, several studies that have recently evaluated the quality of ICD-10-based asthma diagnoses in the Danish National Registry of Patients have found the diagnosis codes to be accurate. ${ }^{17,18}$ One study that used 3,550 medical records as the gold standard to validate ICD-10 inpatient asthma diagnoses recorded in the Danish National Registry of Patients reported $90 \%$ sensitivity and 99\% specificity of asthma diagnoses among children aged 6-14 years old. ${ }^{17}$ Another study reported $44 \%$ sensitivity and $98 \%$ specificity of asthma diagnoses recorded among 18-year-old men reporting for mandatory medical evaluation at the Danish Military Draft Board. The authors of this study subsequently demonstrated that the level of nondifferential asthma misclassification present in the Danish National Registry of Patients 
was not sufficient to nullify the association between asthma and various skin cancers that they examined. ${ }^{18}$

We observed a $6 \%$ prevalence of asthma in our study population, which is less than an estimated asthma prevalence of $10 \%-12 \%$ based on questionnaire data collected from parents of Danish children aged 5-17 years. ${ }^{31,32}$ To determine the potential impact of imperfect sensitivity and specificity of exposure ascertainment on our results, we performed a bias analysis by calculating the IRR that would have been observed if asthma ascertainment only has a sensitivity equal to $50 \%$ and a specificity equal to $97 \%$. This sensitivity is consistent with the differences between the asthma prevalence recorded in this study and that recorded in published reports, and this specificity was the minimum specificity that resulted in no negative cell frequency in the corrected table. We assumed that exposure misclassification was nondifferential and independent for cases and noncases, as the data in our study were prospectively collected. The results from this analysis indicated a minimal impact on the age-specific IRRs: the unadjusted IRR in children aged 6 to $<24$ months old would increase from 2.3 to 2.4 and the IRR among children 24 to $<60$ months old would increase from 4.8 to 5.0; the unadjusted IRRs among children 0 to $<6$ months old and $\geq 60$ months old would not change.

Second, the exclusive use of ICD-10 codes to identify PD cases creates the potential for misclassification. Some PD cases could have been missed if the resulting illness was mild, if cultures were falsely negative, or due to recordkeeping errors. However, because PD is a serious disease typically requiring medical treatment, ICD-10 codes are likely to capture the most important and costly infections. If underascertainment of PD did occur, it was likely to be nondifferential due to the prospective nature of the data which is, in turn, expected to produce unbiased ratio effect estimates ${ }^{33}$ in the absence of false positives. It is, however, possible that some cases could have been falsely attributed to PD when in fact they were caused by other bacterial infections. Although we did not independently verify case status in this study, discharge diagnoses of PD have been found to have high specificity in validation studies conducted by other investigators. ${ }^{16,34}$

Third, although we were able to collect extensive information about pregnancy- and birth-related characteristics, we were not able to capture complete information about some social factors associated with PD. Misclassification of exposure to secondary tobacco smoke ${ }^{35}$ may have occurred in this study because information about smoking was only available from mothers at the beginning of pregnancy, and no information was available from fathers or other childcare providers. In addition, we were not able to identify which children attended daycare. ${ }^{20}$

\section{Conclusion}

Despite these limitations, the current study is an important contribution to the current knowledge of the association between asthma and PD. The evidence presented here indicates that asthmatic children are more likely to develop PD compared with nonasthmatic children, thereby providing support for the addition of asthma to the list of pneumococcal vaccine-eligible conditions for older children. These results also indicate that children who have asthma and another underlying comorbidity may be at especially high risk of PD, and should be carefully assessed in the clinic when presenting with bacterial illnesses.

\section{Author contributions}

Kimberly M Shea: Dr Shea oversaw all aspects of the study including conceiving of the study idea, preparing the dataset, conducting the analyses, and drafting the initial manuscript. Timothy L Lash, Susan S Jick, and Henrik T Sørensen: Drs Lash, Jick, and Sørensen assisted with the design of the study, participated in the interpretation of the results, reviewed and revised the manuscript, and approved the final manuscript for submission. Sussie Antonsen: Ms Antonsen prepared the original dataset, assisted with the statistical analyses, reviewed and revised the manuscript, and approved the final manuscript for submission.

\section{Disclosure}

The authors report no conflicts of interest in this work.

\section{References}

1. Prevention of pneumococcal disease: recommendations of the Advisory Committee on Immunization Practices (ACIP). MMWR Recomm Rep. 1997;46(RR-8):1-24.

2. Talbot TR, Hartert TV, Mitchel E, et al. Asthma as a risk factor for invasive pneumococcal disease. N Engl J Med. 2005;352(20):2082-2090.

3. Juhn YJ, Kita H, Yawn BP, et al. Increased risk of serious pneumococcal disease in patients with asthma. J Allergy Clin Immunol. 2008;122(4):719-723.

4. Watt JP, O'Brien KL, Benin AL, et al. Risk factors for invasive pneumococcal disease among Navajo adults. Am J Epidemiol. 2007;166(9):1080-1087.

5. Klemets P, Lyytikäinen O, Ruutu P, et al. Risk of invasive pneumococcal infections among working age adults with asthma. Thorax. 2010;65(8):698-702.

6. Hjuler T, Wohlfahrt J, Staum Kaltoft M, Koch A, Biggar RJ, Melbye M. Risks of invasive pneumococcal disease in children with underlying chronic diseases. Pediatrics. 2008;122(1):e26-e32.

7. World Health Organization [webpage on the Internet]. WHO factsheet 307: asthma. Geneva, Switzerland: World Health Organization. Available from: http://www.who.int/mediacentre/factsheets/fs307/en/index.html. Accessed March 30, 2014. 
8. Sunyer J, Antó JM, Tobias A, Burney P. Generational increase of self-reported first attack of asthma in fifteen industrialized countries. European Community Respiratory Health Study (ECRHS). Eur Respir J. 1999;14(4):885-891.

9. Hartert TV, Peebles RS. Epidemiology of asthma: the year in review. Curr Opin Pulm Med. 2000;6(1):4-9.

10. Mannino DM, Homa DM, Akinbami LJ, Moorman JE, Gwynn C, Redd SC. Surveillance for asthma - United States, 1980-1999. MMWR Surveill Summ. 2002;51(1):1-13.

11. Centers for Disease Control and Prevention (CDC). Asthma prevalence and control characteristics by race/ethnicity - United States, 2002. MMWR Morb Mortal Wkly Rep. 2004;53(7):145-148.

12. Asher MI, Montefort S, Björkstén B, et al; ISAAC Phase Three Study Group. Worldwide time trends in the prevalence of symptoms of asthma, allergic rhinoconjunctivitis, and eczema in childhood: ISAAC Phases One and Three repeat multicountry cross-sectional surveys. Lancet. 2006;368(9537):733-743.

13. Harboe ZB, Valentiner-Branth P, Benfield TL, et al. Early effectiveness of heptavalent conjugate pneumococcal vaccination on invasive pneumococcal disease after the introduction in the Danish Childhood Immunization Programme. Vaccine. 2010;28(14):2642-2647.

14. Pedersen CB, Gøtzsche H, Møller JO, Mortensen PB. The Danish Civil Registration System. A cohort of eight million persons. Dan Med Bull. 2006;53(4):441-449.

15. Department of Clinical Epidemiology, Aarhus University Hospital. National Registries, hosted and run by the National Board of Health. In: Sørensen HT, Christensen T, Schlosser HK, Pedersen L, editors. Use of Medical Databases in Clinical Epidemiology. 2nd ed. Aarhus, Denmark: Sun-Tryk, Aarhus University; 2009:23-29.

16. Mahon BE, Ehrenstein V, Nørgaard M, Pedersen L, Rothman KJ, Sørensen HT. Perinatal risk factors for hospitalization for pneumococcal disease in childhood: a population-based cohort study. Pediatrics. 2007;119(4):e804-e812.

17. Moth G, Vedsted P, Schiøtz PO. National registry diagnoses agree with medical records on hospitalized asthmatic children. Acta Paediatr. 2007;96(10):1470-1473.

18. Jensen AØ, Nielsen GL, Ehrenstein V. Validity of asthma diagnoses in the Danish National Registry of Patients, including an assessment of impact of misclassification on risk estimates in an actual dataset. Clin Epidemiol. 2010;2:67-72.

19. Knudsen LB, Olsen J. The Danish Medical Birth Registry. Dan Med Bull. 1998;45(3):320-323.
20. Butler J. Epidemiology of pneumococcal disease. In: Tuomanen E, Mitchell T, Morrison D, Spratt B, editors. The Pneumococcus. Washington, DC: ASM Press; 2004:148-168.

21. Rothman KJ. The estimation of synergy or antagonism. Am J Epidemiol. 1976;103(5):506-511.

22. Greenland S, Lash TL, Rothman KJ. Concepts of interaction. In: Rothman KJ, Greenland S, Lash TL, editors. Modern Epidemiology. 3rd ed. Philadelphia, PA: Lippincott, Williams and Wilkins, 2008;74-83.

23. SAS 9.2; SAS Institute Inc., Cary, NC, USA.

24. Olson LM, Radecki L, Frintner MP, Weiss KB, Korfmacher J, Siegel RM. At what age can children report dependably on their asthma health status? Pediatrics. 2007;119(1):e93-e102.

25. Bisgaard H, Hermansen MN, Buchvald F, et al. Childhood asthma after bacterial colonization of the airway in neonates. $N$ Engl J Med. 2007;357(15):1487-1495.

26. Cardozo DM, Nascimento-Carvalho CM, Andrade AL, et al. Prevalence and risk factors for nasopharyngeal carriage of Streptococcus pneumoniae among adolescents. J Med Microbiol. 2008;57(Pt 2):185-189.

27. Fahy JV, Corry DB, Boushey HA. Airway inflammation and remodeling in asthma. Curr Opin Pulm Med. 2000;6(1):15-20.

28. Busse WW. Pathogenesis and sequelae of respiratory infections. Rev Infect Dis. 1991;13 Suppl 6:S477-S485.

29. Bardin PG, Fraenkel DJ, Sanderson G, et al. Amplified rhinovirus colds in atopic subjects. Clin Exp Allergy. 1994;24(5):457-464.

30. Message SD, Johnston SL. Host defense function of the airway epithelium in health and disease: clinical background. J Leukoc Biol. 2004;75(1):5-17.

31. Thomsen SF, Ulrik CS, Larsen K, Backer V. Change in prevalence of asthma in Danish children and adolescents. Ann Allergy Asthma Immunol. 2004;92(5):506-511.

32. Hermann C, De Fine Olivarius N, Høst A, Begtrup K, Hollnagel H. Prevalence, severity and determinants of asthma in Danish five-yearolds. Acta Paediatr. 2006;95(10):1182-1190.

33. Greenland S, Lash TL. Validity in epidemiologic studies. In: Rothman KJ, Greenland S, Lash TL, editors. Modern Epidemiology. 3rd ed. Philadelphia, PA: Lippincott, Williams \& Wilkins; 2008;142-143.

34. Kristensen J, Langhoff-Roos J, Skovgaard LT, Kristensen FB. Validation of the Danish Birth Registration. J Clin Epidemiol. 1996;49(8):893-897.

35. Nuorti JP, Butler JC, Farley MM, et al. Cigarette smoking and invasive pneumococcal disease. Active Bacterial Core Surveillance Team. N Engl J Med. 2000;342(10):681-689. 


\section{Supplementary materials \\ Evaluation of observed effect measure modification for evidence of biologic interaction}

Effect measure modification observed in stratified analyses was further evaluated for evidence of biologic interaction by using three standard measures ${ }^{1,2}$ to determine whether the independent effects of asthma and comorbidity summed to the total effect of both factors together.

First, the interaction contrast (IC) between asthma and comorbidity was calculated by applying the following formula to crude pneumococcal disease (PD) incidence rates per 100,000 person years:

$$
I C=R_{E+C+}-R_{E+C-}-R_{E-C+}+R_{E-C-}
$$

Table SI ICD-I 0 codes used to identify asthma, pneumococcal disease, and comorbidities from Danish registries

\begin{tabular}{|c|c|}
\hline & ICD- I 0 code \\
\hline Clinical diagnoses & $\mathrm{J} 45$ and $\mathrm{J} 46$ \\
\hline \multicolumn{2}{|l|}{ Pneumococcal disease } \\
\hline Pneumococcal meningitis & G00.I \\
\hline Pneumococcal septicemia & A40.3 \\
\hline Pneumococcal pneumonia & A40.4 \\
\hline \multicolumn{2}{|l|}{ Comorbidity } \\
\hline HIV & B20-B24 \\
\hline $\begin{array}{l}\text { Sickle cell disease and other } \\
\text { sickle cell hemoglobinopathies, } \\
\text { congenital or acquired asplenia, } \\
\text { or splenic dysfunction }\end{array}$ & D57.0-D57.3; D57.8; Q89.0; D730 \\
\hline Nonasthma COPD & $\begin{array}{l}\text { J4I-J44; J47; J60-J67; J68.4; J70.I; } \\
\text { J70.3; J84.I; J92.0; J96.I; J98.2-J98.3; } \\
\text { P23; P25; P27; P29; E84 }\end{array}$ \\
\hline $\begin{array}{l}\text { Cardiac disease, including } \\
\text { congenital heart disease }\end{array}$ & $\begin{array}{l}\text { I05-I09; III-II3; I20-I28; I3I; } \\
\text { I34-I37; I42-I45; I50-I5I; Q20-Q28 }\end{array}$ \\
\hline $\begin{array}{l}\text { Cancer or immunosuppression, } \\
\text { including transplant recipients } \\
\text { and immune function disorders }\end{array}$ & $\begin{array}{l}\text { C00-C26; C30-C34; C37-C39; } \\
\text { C4I; C43-C85; C88; C90-C97; } \\
\text { Z85; D80-D84; D86; D89; } \\
\text { T86.0-T86.4; T86.8; Y83.0; Y84.0- } \\
\text { Y84.I; Z94.0-Z94.4; Z94.8; Z96.2; } \\
\text { Z98.2; Z99.0-Z99.2; Z45.3 }\end{array}$ \\
\hline $\begin{array}{l}\text { Chronic renal or hepatic } \\
\text { disease, including cirrhosis }\end{array}$ & $\begin{array}{l}\text { BI5.0; BI6.0; BI6.2; BI8; BI9.0; } \\
\text { II2; II3; K70-K76; N03-N05; } \\
\text { N07; NII; NI4; NI8-NI9; P96.0; } \\
\text { Q60-Q6I; Q63 }\end{array}$ \\
\hline Diabetes mellitus & EIO-EI4 \\
\hline Congenital infection & P36 and P37 \\
\hline
\end{tabular}

Abbreviation: ICD, International Classification of Diseases. where $R$ represents the rate of disease, $E$ represents exposure to asthma, and $C$ is the modifying covariate which, in this case, was comorbidity. The IC represents the number of cases of disease (per 100,000 child-years) that cannot be accounted for by baseline factors among children without asthma or comorbidity, asthma only, or comorbidity only, and is therefore presumed to be attributable to a biological interaction between asthma and comorbidity.

Next, the interaction contrast ratio (ICR) and 95\% confidence interval around the ICR was calculated to quantify the excess rate when both asthma and comorbidity were present at the same time relative to the baseline rate of disease that occurred when neither were present, while adjusting for important confounders of the association between asthma and $\mathrm{PD}:{ }^{3}$

$$
I C R=\frac{I C}{R_{E-C-}}=I R R_{E+C+}-I R R_{E+C-}-I R R_{E-C+}+1
$$

The ICRs in our study were adjusted for sex, birth weight, child year of birth, and congenital malformation. We then used the ICR (to account for confounders) to calculate the attributable proportion due to interaction (AP), which quantifies the proportion of disease among exposed persons attributable to the interaction between an exposure and a modifying covariate. The AP was calculated by dividing the ICR by the IRR, comparing children with asthma and comorbidity to children without either of these: ${ }^{3}$

$$
A P=\frac{I C R}{I R R_{E+C+}}=\frac{I R R_{E+C+}-I R R_{E+C-}-I R R_{E-C+}+1}{I R R_{E+C+}}
$$

\section{References}

1. Rothman KJ. The estimation of synergy or antagonism. Am J Epidemiol. 1976;103(5):506-511.

2. Greenland S, Lash TL, Rothman KJ. Concepts of interaction. In: Rothman KJ, Greenland S, Lash TL, editors. Modern Epidemiology. 3rd ed. Philadelphia, PA: Lippincott, Williams and Wilkins; 2008.

3. Andersson T, Alfredsson L, Kallberg H, Zdravkovic S, Ahlbom A. Calculating measures of biological interaction. Eur J Epidemiol. 2005;20:575-579. 


\section{Publish your work in this journal}

Clinical Epidemiology is an international, peer-reviewed, open access, online journal focusing on disease and drug epidemiology, identification of risk factors and screening procedures to develop optimal preventative initiatives and programs. Specific topics include: diagnosis, prognosis, treatment, screening, prevention, risk factor modification,

Submit your manuscript here: http://www.dovepress.com/clinical-epidemiology-journal systematic reviews, risk \& safety of medical interventions, epidemiology \& biostatistical methods, and evaluation of guidelines, translational medicine, health policies \& economic evaluations. The manuscript management system is completely online and includes a very quick and fair peer-review system, which is all easy to use. 